\title{
Emerging Role of Schwann Cells in Neuropathic Pain: Receptors, Glial Mediators and Myelination
}

\author{
Zhongya Wei ${ }^{1}$, Ying $\mathrm{Fei}^{1}$, Wenfeng Su ${ }^{1}$ and Gang Chen ${ }^{1,2 *}$ \\ ${ }^{1}$ Key Laboratory of Neuroregeneration of Jiangsu and Ministry of Education, Co-innovation Center of Neuroregeneration, \\ Nantong University, Nantong, China, ${ }^{2}$ Department of Anesthesiology, Affiliated Hospital of Nantong University, Nantong, \\ China
}

Neuropathic pain caused by nerve injury or disease remains a major challenge for modern medicine worldwide. Most of the pathogenic mechanisms underlying neuropathic pain are centered on neuronal mechanisms. Accumulating evidence suggests that non-neuronal cells, especially glial cells, also play active roles in the initiation and resolution of pain. The preponderance of evidence has implicated central nervous system (CNS) glial cells, i.e., microglia and astrocytes, in the control of pain. The role of Schwann cells in neuropathic pain remains poorly understood. Schwann cells, which detect nerve injury and provide the first response, play a critical role in the development and maintenance of neuropathic pain. The cells respond to nerve injury by changing their phenotype, proliferating and interacting with nociceptive neurons by releasing glial mediators (growth factors, cytokines, chemokines, and biologically active small molecules). In addition, receptors expressed in active Schwann cells have the potential to regulate different pain conditions. In this review article, we will provide and discuss emerging evidence by integrating recent advances related to Schwann cells and neuropathic pain.

\section{OPEN ACCESS}

Edited by:

Stefania Ceruti,

University of Milan, Italy

Reviewed by:

Livio Luongo,

Second University of Naples, Italy

Valerio Magnaghi,

University of Milan, Italy

${ }^{*}$ Correspondence:

Gang Chen

chengang6626@ntu.edu.cn

Received: 31 December 2018 Accepted: 11 March 2019

Published: 27 March 2019

Citation:

Wei Z, Fei Y, Su W and Chen G (2019) Emerging Role of Schwann Cells in Neuropathic Pain: Receptors,

Glial Mediators and Myelination.

Front. Cell. Neurosci. 13:116.

doi: 10.3389/fncel.2019.00116
Keywords: Schwann cells, neuropathic pain, receptors, glial mediators, myelination

\section{INTRODUCTION}

Neuropathic pain is a typically persistent and intractable type of chronic pain. This condition is not a symptom of a disorder but a pathological state caused by a primary lesion or dysfunction in the nervous system (Backonja, 2003). It is well known that neuropathic pain is an expression of neuroplasticity and arises from both the peripheral nervous system (PNS) and the central nervous system (CNS).

Past research on neuropathic pain has focused mostly on the role of neurons (Ji et al., 2003; Chen et al., 2016, 2017). Following a nerve injury, both peripheral and central sensitization act as important disease mechanisms, including sensitization and hyperexcitability of primary sensory neurons as well as enhanced excitatory synaptic transmission or reduced inhibitory synaptic transmission in the neurons of the CNS (Gold and Gebhart, 2010; Kuner, 2010). In parallel to the changes in the activity of neuronal systems, non-neuronal cells, especially glial cells, are increasingly recognized as important in the development and maintenance of neuropathic pain (Ji et al., 2013, 2016). Regarding the glial cells in the CNS, both astrocytes and microglia have well-documented roles in the regulation of neuropathic pain, primarily in the spinal cord and brain (Ji et al., 2013, 2016; Chen et al., 2014, 2018).

The glial cells of the PNS primarily include Schwann cells and satellite glial cells. The satellite glial cells surrounding the somata of dorsal root ganglion (DRG) neurons are activated 


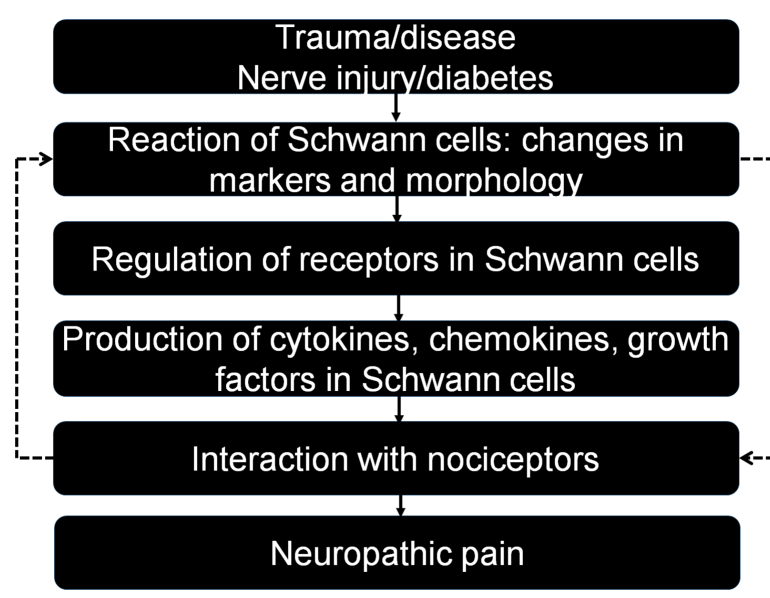

FIGURE 1 | Interactions between Schwann cells and neurons in different pain conditions after trauma and disease. Note that Schwann cells can modulate neuropathic pain in different directions by producing relevant mediators that act on specific receptors. Activated neurons also have a feedback effect on Schwann cells, completing an interaction loop.

prior to central glial cells after nerve injury and play a critical role in the development of neuropathic pain (Jasmin et al., 2010; Ji et al., 2013). Schwann cells not only physically support the long axons but also release a variety of growth factors to nourish and myelinate the large associated axons (Chen et al., 2012; Kidd et al., 2013; Su et al., 2016). After sciatic nerve injury, activated Schwann cells undergo dramatic changes in response, including phenotype modulation, proliferation, migration and release of numerous factors, which eventually promote nerve regeneration (Scheib and Höke, 2013). It is well known that nerve injury is of utmost importance in the generation of neuropathic pain. Thus, Schwann cells play a key role in the study of neuropathic pain, but little is known about how these cells regulate this condition. In this review article, we will discuss and update the current knowledge of how Schwann cells modulate neuropathic pain, and we will provide an improved understanding of the underlying mechanisms (Figure 1).

\section{SCHWANN CELLS AND THEIR MULTIPOTENCY}

Schwann cells, the most abundant glial cells in the PNS, include two major phenotypes: myelinating Schwann cells and nonmyelinating Schwann cells. Both types originate from embryonic Schwann cell precursors derived from the neural crest. Initially, these cells surround the external margins of the axon bundles (Kidd et al., 2013). Schwann cells support axonal outgrowth during this stage by producing a variety of growth factors, such as nerve growth factor (NGF), glial cell line-derived neurotrophic factor (GDNF), and brain-derived neurotrophic factor (BDNF; Kidd et al., 2013). While maturing and interacting with axons, myelinating Schwann cells wrap larger axons at a one-toone ratio to produce a myelin sheath, while nonmyelinating Schwann cells embed smaller axons, forming a Remak bundle (Kidd et al., 2013).
After nerve injury, the former myelinating cells degrade their myelin and become a class of nonmyelinating cells, repair Schwann cells, which regain their developmental potential, including the capacity for proliferation, growth factor production, sorting, or sprouting and myelination if they receive the suitable neuronal signals (Griffin and Thompson, 2008; Scheib and Höke, 2013). Importantly, signaling systems that are crucial for the development of the Schwann cell lineage, but they have no or little role in the generation of repair Schwann cells and nerve regeneration (Jessen and Arthur-Farraj, 2019). This encourages the view that the different phenotype of Schwann cells and their transitions are likely to play a different role in regulating neuropathic pain, but it still awaits the selective tools to control the particular cells and reveal their specific role in the process of neuropathic pain. Notably, multiple receptors, channels and active molecules are altered or activated in different neuropathic pain conditions. Glial mediators, including cytokines, chemokines and growth factors are produced and secreted from activated Schwann cells.

\section{RECEPTORS, CHANNELS AND ACTIVE MOLECULES OF SCHWANN CELLS MEDIATE NEUROPATHIC PAIN}

As shown in Table 1, multiple receptors and channels are expressed in Schwann cells and regulated in different pain conditions. Although these molecules are not released, they activate intracellular signaling to release growth factors, cytokines, and chemokines that regulate pain states (Table 2).

Adenosine triphosphate (ATP) is an important molecule in the process of pain information transmission (Kuan and Shyu, 2016). This substance modulates glial activation primarily via activating the P2X ion channel receptor and the G-proteincoupled receptor (GPCR)-coupled receptor P2Y (Lecca et al., 2012). Although both P2X and P2Y receptors are expressed in Schwann cells, accumulating evidence shows that $\mathrm{P} 2 \mathrm{X}$ receptors play a critical role in the regulation of neuropathic pain (Mayer et al., 1998). mRNAs for all P2X receptor subtypes are detectable in Schwann cells, with P2X4-7 receptors being highly expressed (Su et al., 2019). In vivo and in vitro experiments have revealed that the expression of the P2X4 receptor is markedly upregulated in Schwann cells of injured nerves. Blocking the P2X4 receptor in microglia can reverse established pain hypersensitivity after nerve injury, and the development of pain hypersensitivity after nerve injury is prevented in P2X4 receptor knockout mice (Tsuda et al., 2003; Ulmann et al., 2008). However, we did not observe increased pain hypersensitivity in mice with specific overexpression of the P2X4 receptor in Schwann cells compared with the control group (Su et al., 2019). While the expression of P2X7 receptor in Schwann cells and Schwann cell-like adipose-derived stem cells has been found to contribute to ATP-induced cell death (Faroni et al., 2013). Notably, the study from P2X7 knockout mice has revealed that P2X7 knockout nerves possess more unmyelinated axons containing a higher number of Remak bundle, which increase nociception (Faroni et al., 2014b). Another report regarding Schwann cells involved in regulating neuropathic pain shows 
TABLE 1 | Regulation of receptors and active molecules in Schwann cells in neuropathic pain.

\begin{tabular}{|c|c|c|c|}
\hline Molecule & Classification & Change after nerve injury & References \\
\hline P2X4R & Receptor & $\uparrow$ & Su et al. (2019) \\
\hline $\mathrm{P} 2 \times 2 / 3 \mathrm{R}$ & Receptor & $\uparrow$ & Zhang et al. (2018) \\
\hline $\mathrm{P} 2 \mathrm{X7R}$ & Receptor & - & Faroni et al. (2014b) \\
\hline TLR2 & Receptor & $\uparrow$ & Boivin et al. (2007) and Lee et al. (2013) \\
\hline LRP1 & Receptor & $\downarrow$ & Campana et al. (2006a) and Orita et al. (2013) \\
\hline TRPA1 & Channel & $\uparrow$ & De Logu et al. (2017) \\
\hline LPA1 R & Receptor & $\uparrow$ & Inoue et al. (2004) \\
\hline HCAR2 & Receptor & $\uparrow$ & Boccella et al. (2019) \\
\hline GABA-B & Receptor & - & Faroni et al. (2014a) and Magnaghi et al. (2014) \\
\hline $\mathrm{MHC}-\|$ & Antigen & $\uparrow$ & Hartlehnert et al. (2017) \\
\hline ErbB & Receptor & - & Chen et al. (2006) \\
\hline gp120 & Glycoprotein & - & Keswani et al. (2006) \\
\hline
\end{tabular}

Purinergic receptors: P2X4R, P2X2/3R, P2X7R; TLR2, Toll-like receptor 2; LRP1, LDL receptor-related protein 1; TRPA1, Transient receptor potential Ankyrin 1; LPA1 R, Lysophosphatidic acid 1 receptor; HCAR2, Hydroxyl carboxylic acid receptor type 2; GABA-B, $\gamma$-aminobutyric acid type B receptor; MHC-II, Class II major histocompatibility complex; ErbB, Epidermal growth factor receptor; gp120, HIV-1 envelope glycoprotein. Symbols: $\uparrow$ denotes upregulation or activation; $\downarrow$ denotes downregulation or inactivation; - denotes data unavailable.

\begin{tabular}{|c|c|c|c|}
\hline Mediator & Classification & Change after nerve injury & References \\
\hline TNF- $\alpha$ & Proinflammatory cytokine & $\uparrow$ & Scholz and Woolf (2007) and Sacerdote et al. (2008) \\
\hline IL-1 & Proinflammatory cytokine & $\uparrow$ & Martucci et al. (2008) \\
\hline IL-6 & Proinflammatory cytokine & $\uparrow$ & Martucci et al. (2008) \\
\hline IL-10 & Anti-inflammatory cytokine & $\downarrow$ & Franchi et al. (2012) and Wang et al. (2012) \\
\hline Epo & Anti-inflammatory cytokine & $\uparrow$ & Keswani et al. (2004) and Campana et al. (2006b) \\
\hline $\operatorname{cox} 2$ & Chemokine & $\uparrow$ & Takahashi et al. (2004) \\
\hline MCP-1 & Chemokine & $\uparrow$ & Toews et al. (1998) and De Logu et al. (2017) \\
\hline BDNF & Growth factor & $\uparrow$ & Yajima et al. (2005) and Su et al. (2019) \\
\hline ATP & Messenger molecule & $\uparrow$ & Martucci et al. (2008) \\
\hline
\end{tabular}

TNF- $\alpha$, Tumor necrosis factor- $\alpha$; IL-1, IL-6, IL-10, Interleukin related cytokine; Epo, Erythropoietin; COX-2, Cyclooxygenase-2; MCP-1, Monocyte chemoattractant protein-1; BDNF, Brain derived neurotrophic factor; ATP, Adenosine triphosphate. Symbols: $\uparrow$ denotes upregulation or activation; $\downarrow$ denotes downregulation or inactivation.

that the transplantation of microencapsulated Schwann cells can alleviate neuropathic pain by inhibiting $\mathrm{P} 2 \mathrm{X} 2 / 3$ receptor overexpression in sciatic nerve injury (Zhang et al., 2018). The underlying mechanism of upregulation of $\mathrm{P} 2 \mathrm{X}$ receptors in nerve injury is centered on the enhancement of BDNF release (Ulmann et al., 2008; Su et al., 2019), while the other mechanisms are still unclear.

Toll-like receptors (TLRs) are known to regulate innate immunity and have been strongly linked to the activation of glial cells (Nicotra et al., 2012). TLR2, 3 and 4 are highly expressed in Schwann cells at both the mRNA and protein levels (Lee et al., 2013). Lee et al. (2013) found that necrotic sensory neurons induced the release of proinflammatory mediators such as tumor necrosis factor- $\alpha$ (TNF- $\alpha)$ and iNOS by cultured rat Schwann cells from wild-type mice but not those from TLR2 knockout mice, suggesting that Schwann cells are activated through TLR2 recognition of damage-associated molecular patterns (DAMPs) during nerve injury. Notably, an in vivo study by Boivin et al. (2007) demonstrated that the Wallerian degeneration and expression of proinflammatory molecules induced by nerve injury were severely impaired in TLR2-knockout mice. Strikingly, the male specificity of the involvement of spinal TLR4 in neuropathic pain suggests a sex difference in TLR4 and microglial signaling (Sorge et al., 2011). Despite the lack of evidence that Schwann cells are involved in the sex difference in TLR signaling in neuropathic pain, any research to develop a TLR-antagonist analgesic or characterize a Tlr mutation must take the effect of sex differences into account if such information is available.

The endocytic transmembrane receptor known as LDL receptor-related protein 1 (LRP1) is a potent regulator of Schwann cells that orchestrates many of the physiological changes and the activation of Schwann cells after injury (Campana et al., 2006a; Mantuano et al., 2011). When Schwann cells lose LRP1 function through a cell-type-specific deletion in scLRP1 $1^{-/}$mice or through an antagonist of the receptorassociated protein, both the survival and the function of those cells are compromised (Campana et al., 2006a; Orita et al., 2013). Prior to nerve injury, LRP1 gene deletion in Schwann cells resulted in the activation of regeneration-associated genes in DRG neurons and the potential to cause chronic pain. Although the presence of abnormal Schwann cells in scLRP1 ${ }^{-/-}$mice primed injured DRG neurons to develop neuropathic pain, nerve repair in scLRP1 $1^{-/-}$mice was associated with abnormalities in ultrastructure and primarily in Remak bundles (Orita et al., 2013; Boivin et al., 2007).

It is well known that transient receptor potential ankyrin 1 (TRPA1) channels are highly expressed by a subpopulation of primary sensory neurons (Story et al., 2003). TRPA1 has been shown to mediate mechanical hypersensitivity in different 
types of neuropathic pain, including those induced by peripheral nerve injury (Eid et al., 2008). In 2017, TRPA1 was found to be expressed in Schwann cells both in cultures and in the sciatic nerve trunk (De Logu et al., 2017). The same study found that TRPA1 silencing in nociceptors attenuated mechanical allodynia without affecting macrophage infiltration, whereas TRPA1 silencing in Schwann cells reduced both mechanical allodynia and neuroinflammation. Activation of Schwann cell TRPA1 induces and maintains macrophage infiltration to the injured nerve and sends paracrine signals to activate TRPA1 in ensheathed nociceptors to sustain mechanical allodynia (De Logu et al., 2017).

Lysophosphatidic acid (LPA) is a bioactive lipid that interacts with specific GPCRs (Ishii et al., 2004). At least three specific LPA receptors are expressed in Schwann cells, and this cell type is known to primarily express the LPA1 receptor (Weiner et al., 2001). The LPA1 receptor is upregulated following sciatic nerve injury, and Schwann cells cultured from LPA1-null mice exhibit greatly diminished morphological responses to LPA (Weiner et al., 2001). Intrathecal injection of LPA induced morphological, biochemical and behavioral changes similar to those observed after nerve injury. However, mice lacking the LPA1 receptor do not develop signs of neuropathic pain after peripheral nerve injury, suggesting that receptor-mediated LPA signaling is crucial in the initiation of neuropathic pain (Inoue et al., 2004). Although there is no direct, accurate evidence characterizing the role of Schwann cell LPA1 receptors in neuropathic pain, the LPA1 receptor is a critical factor in the mediation of neuropathic pain by Schwann cells.

Hydroxyl carboxylic acid receptor type 2 (HCAR2), another class of GPCR is primarily expressed on adipocytes, peripheral immune cells and brain microglia, and involved in lipogenesis, inflammatory processes (Offermanns, 2017). Recently, the HCAR2 expression has been highlighted in the sciatic nerve, primarily in cells positive for $\mathrm{S} 100$ specifically marked by Schwann cells. An up-regulation of HCAR2 in the sciatic nerve and the DRG is present in neuropathic mice. Moreover, the HCAR2 endogenous ligand $\beta$-hydroxybutyrate can reduce the tactile allodynia in neuropathic pain models in female but not male mice. But the effect only occurs in wild-type mice but not in the HCAR2-null mice (Boccella et al., 2019). Although HCAR2 is not specifically expressed in Schwann cells, and do not have the evidence to investigate its role in conditional knockout mouse models, HCAR2 may be a new receptor for the regulation of neuropathic pain.

$\gamma$-aminobutyric acid type $B$ (GABA-B) receptor, is one of the native targets of GABA, and mediates the inhibitory transmission in the CNS. Emerging evidence of GABA-B receptor functions in the PNS suggest its contribution in regulating maturation and plasticity of Schwann cells (Magnaghi et al., 2006). Both GABA-B1 and GABA-B2 receptors are present in neurons, and also in Schwann cells (Magnaghi et al., 2004). The conditional mice with specific deletion of GABA$B$ receptors in Schwann cells are hyperalgesic and allodynia, which associated with a morphological phenotype characterized by a peculiar increase in the number of small unmyelinated fibers and Remak bundles, including nociceptive C-fibers
(Procacci et al., 2012; Faroni et al., 2014a). Meanwhile, GABA$B$ receptor activation following GABA-B ligands treatments with baclofen and CGP56433, promotes nerve regeneration and ameliorates neuropathic pain (Magnaghi et al., 2014). These findings support the importance of GABA-B receptors in the peripheral myelination process, and in modulating the nociceptive fiber activity.

The class II major histocompatibility complex (MHC-II) is presented on the surfaces of antigen presenting cells (APCs) for recognition by $\mathrm{T}$ cells. The main professional APCs are dendritic cells, macrophages and B cells (Neefjes et al., 2011). However, under traumatic and inflammatory conditions, Schwann cells have the potential to express MHC-II and present antigens (Meyer zu Hörste et al., 2010a,b). Notably, Schwann cells upregulate MHC-II under traumatic conditions in female but not male rats (Liu et al., 2012). MHC-II on Schwann cells activates $\mathrm{T}$ helper cells and promotes posttraumatic axon loss and subsequent neuropathic pain. Meanwhile, deletion of MHC-II in myelinating Schwann cells can diminish mechanical allodynia and thermal hyperalgesia in a chronic constriction injury (CCI) model in female mice (Hartlehnert et al., 2017).

Other interesting examples suggest that Schwann cells directly control the development of neuropathic pain. Deficiency of the Neuregulin/ErbB cell signaling pathway induces an enhanced response to mechanical allodynia but no changes in thermal hyperalgesia (Chen et al., 2006). In addition, mice expressing the HIV-1 envelope glycoprotein gp120 in nonmyelinating Schwann cells and treated with didanosine, an antiretroviral drug, had changes in sensory function (thermal allodynia; Keswani et al., 2006). Another candidate target is the acetylcholine system. Botulinum neurotoxins, an inhibitor of acetylcholine neurotransmitter release, exerting their action by cleaving soluble NSF attachment proteins, SNARE proteins, is well established in the treatment of neuropathic pain (Oh and Chung, 2015). In vitro experiments showed that Botulinum neurotoxins was able to interact with the proliferative state of Schwann cells, and facilitate Schwann cell proliferation (Marinelli et al., 2012). Moreover, acetylcholine receptors are present on Schwann cell membrane, and the activation of acetylcholine receptors can induce myelin structure reorganization (Verdiyan et al., 2016). Although there is no direct evidence to strongly characterize the role of Schwann cell acetylcholine system in neuropathic pain, these studies indicate that Botulinum neurotoxins may regulate the function of Schwann cells by the acetylcholine system to reduce neuropathic pain.

\section{REGULATION OF GROWTH FACTORS, CYTOKINES, AND CHEMOKINES IN SCHWANN CELLS IN NEUROPATHIC PAIN}

In response to nerve injury, glial mediators produced or released by activated Schwann cells or recruited immune cells are also a key issue in the control of neuropathic pain by Schwann cells. As shown in Table 2, Schwann cells produce both large molecules, such as growth factors, cytokines and chemokines, 
and small molecules, including ATP. These mediators from Schwann cells play a critical role in neuronal and synaptic activity as well as pain.

Proinflammatory cytokines such as TNF- $\alpha$, IL-1, and IL-6 are well-studied glial mediators. The expression levels of these molecules are upregulated in the sciatic nerve, spinal cord and DRG of animals after CCI (Martucci et al., 2008). Activated Schwann cells and infiltrating macrophages release these mediators, which contribute to axonal damage and enhance nociceptor activity (Campana, 2007; Sacerdote et al., 2008). TNF, the most prominent proinflammatory cytokine, is detectable as early as $6 \mathrm{~h}$ after sciatic nerve injury but has no significant difference from the control group within 7 days after nerve injury (Scholz and Woolf, 2007). Activated resident Schwann cells and macrophages are thought to be the sources for TNF production in the early stage of sciatic nerve injury (Campana, 2007; Sacerdote et al., 2008). IL-1 and IL- 6 are also produced at the onset of injury but have a sustained effect on neuropathic pain. In CCI models, the mRNA levels of these cytokines increase at 1 day after injury, and the levels remain high for up to 21 days after surgery. In addition to the proinflammatory cytokines, anti-inflammatory mediators are also critical to the regulation of neuropathic pain (Martucci et al., 2008). The accumulating reports show that IL-10, the predominant anti-inflammatory mediator, is detected in the sciatic nerve after a lesion develops (Austin and Moalem-Taylor, 2010; Franchi et al., 2012). Meanwhile, several strategies aimed at enhancing the level of endogenous IL-10 have succeeded in preventing and relieving pain hypersensitivity in several neuropathic pain models (Franchi et al., 2012; Wang et al., 2012).

Erythropoietin (Epo), another anti-inflammatory cytokine, is upregulated along with its receptor EpoR after nerve injury, and the primary cellular source of EPO is activated Schwann cells ( $\mathrm{Li}$ et al., 2005). In the early stage of nerve injury, Epo is able to reduce the production of TNF- $\alpha$ and facilitate recovery from chronic pain states (Keswani et al., 2004; Campana et al., 2006b). Therefore, the balance of inflammatory and anti-inflammatory mediators may be a future target for therapeutic intervention.

Chemokines, as another pain modulator, are expressed in neurons as well as in glial cells (Ji et al., 2013, 2016). In Schwann cells, cyclooxygenase-2 (COX-2) and monocyte chemoattractant protein-1 (MCP-1) are expressed after nerve injury (Toews et al., 1998; Takahashi et al., 2004). However, the cellular sources of these molecules differ between the early and late stages of nerve injury. The first increase in the number of positive cells occurred approximately 1 day after nerve injury in Schwann cells coexpressing S-100. The second increase was noted after 7-14 days and these cells were macrophages coexpressing ED-1 (Toews et al., 1998; Takahashi et al., 2004). Notably, a distinct CCL2 and TRPA1/oxidative stress pathway induced macrophage accumulation in Schwann cells (De Logu et al., 2017). Oxidative stress has been thought to exert a chemoattractant effect by macrophage infiltration. NADPH oxidase-1 (NOX1) is noticeably expressed in Schwann cells. TRPA1 in Schwann cells activates a NOX1-mediated intracellular signaling pathway to produce sustained oxidative stress, and it also maintains macrophage infiltration into lesion sites, which induces allodynia by activating TRPA1 on the nociceptors (De Logu et al., 2017).

Growth factors are known to play important roles in neuronal survival, myelination and synaptic plasticity (Park and Poo, 2013). In response to sciatic nerve injury, Schwann cells secrete multiple growth factors, such as NGF, BDNF, and neurotrophin3 and 4 (Scheib and Höke, 2013). Among these factors, we found that TNF- $\alpha$-induced BDNF release beyond the basal level in Schwann cells depends on P2X4R (Su et al., 2019). However, P2X4R-knockout mice do not show pain hypersensitivity after nerve injury, which has an ill effect on the release of intracellular signaling factors, including BDNF (Tsuda et al., 2003). On the other hand, as BDNF is a key mediator of neuropathic pain, BDNF-knockout mice display reduced pain hypersensitivity after nerve lesion compared with wild-type mice (Yajima et al., 2005). However, overexpression of P2X4R in Schwann cells did not result in increased pain hypersensitivity. In addition, intraplantar injection of BDNF induced mechanical allodynia only in naïve mice and not in mice with crush injuries of the sciatic nerve (Su et al., 2019).

ATP is an important intracellular messenger molecule that interacts with purinoceptors, playing a crucial role in the formation and regulation of neuropathic pain (Burnstock, 2006). Several subtypes of P2X receptors are highly expressed in Schwann cells (Su et al., 2019). ATP is released from Schwann cells under physiological conditions, and after nerve injury, increasing levels of ATP play an important role in both peripheral and central sensitization (Martucci et al., 2008; Tsuda et al., 2010). Released ATP activates neurons and Schwann cells to release certain mediators, including proinflammatory cytokines and chemokines (Inoue, 2006). Notably, when the broad-spectrum P2 receptor antagonist pyridoxal phosphate-6azophenyl-2', $4^{\prime}$-disulfonic acid (PPADS) was administered after nerve injury, it significantly reduced the levels of IL-1 and IL-6, decreased tactile allodynia and thermal hyperalgesia, and continued to exert an effect for 2-3 weeks after administration (Martucci et al., 2008).

\section{RELATIONSHIP OF DEMYELINATION AND REMYELINATION WITH NEUROPATHIC PAIN}

It is well established that demyelination contributes to the development of neuropathic pain by disrupting the precise molecular and structural features of nerve fibers. For example, in females specifically, algesic MBP fragments released from the intact myelin sheath after nerve injury via MT1-MMP proteolysis control mechanical allodynia (Hong et al., 2017). The alteration of ErbB signaling in myelination Schwann cells leads to demyelination and induces mechanical hypersensitivity (Tao et al., 2013).

However, a direct relationship between remyelination and pain relief has not been investigated. Several studies have shown 
an indirect association between them. For example, Gabapentin alleviates mechanical and thermal allodynia and improves nerve remyelination after chronic constriction of the sciatic nerve (Camara et al., 2015). Focal lysolecithin-induced demyelination of peripheral afferents results in neuropathic pain behaviors, which are reversible by cannabinoids after nerve remyelination nearly 3 weeks after treatment (Wallace et al., 2003). Our work reveals that the $\mathrm{P} 2 \mathrm{X} 4-\mathrm{LV}$ group is related to improve remyelination and has the potential to reduce the mechanical allodynia induced by sciatic nerve injury (Su et al., 2019). Thus, the accurate relationship of remyelination with neuropathic pain will require further study.

\section{CONCLUSIONS}

Peripheral neuropathic pain is a disorder caused by nerve trauma or disease. In this review article, we mainly discuss the role of Schwann cells in the development and relief of neuropathic pain directly induced by nerve injury. In fact, diabetes may induce several types of neuropathies, resulting in spontaneous pain and eventual loss of pain sensation (Mizisin, 2014; Gonçalves et al., 2017). The state of Schwann cells and their communication with axons might be disturbed, ultimately leading to fiber loss and pain. However, the mechanistic understanding of the Schwann cell response to diabetes is unclear. In addition to the importance of glial receptors and mediators, Schwann cell autophagy represents a powerful approach to prevent the onset and chronification of neuropathic pain (Marinelli et al., 2014). Notably, caloric restriction promotes Schwann cell autophagy via AMP-activated protein kinase and facilitates remyelination in nerve injury, which provides new evidence for Schwann cell autophagy as a therapeutic approach against neuropathic pain (Coccurello et al., 2018). Overall, accumulating evidence has revealed the key role of Schwann cells in the regulation of neuropathic pain. An improved and extended comprehension of the underlying neurobiological mechanisms of neuropathic pain would allow the development of successful targeted pain therapy.

\section{REFERENCES}

Austin, P. J., and Moalem-Taylor, G. (2010). The neuro-immune balance in neuropathic pain: involvement of inflammatory immune cells, immune-like glial cells and cytokines. J. Neuroimmunol. 229, 26-50. doi: 10.1016/j.jneuroim. 2010.08.013

Backonja, M. M. (2003). Defining neuropathic pain. Anesth. Analg. 97, 785-790. doi: 10.1213/01.ane.0000062826.70846.8d

Boccella, S., Guida, F., De Logu, F., De Gregorio, D., Mazzitelli, M., Belardo, C., et al. (2019). Ketones and pain: unexplored role of hydroxyl carboxylic acid receptor type 2 in the pathophysiology of neuropathic pain. FASEB J. 33, 1062-1073. doi: 10.1096/fj.201801033r

Boivin, A., Pineau, I., Barrette, B., Filali, M., Vallieres, N., Rivest, S., et al. (2007). Toll-like receptor signaling is critical for Wallerian degeneration and functional recovery after peripheral nerve injury. J. Neurosci. 27, 12565-12576. doi: 10.1523/JNEUROSCI.3027-07.2007

Burnstock, G. (2006). Purinergic P2 receptors as targets for novel analgesics. Pharmacol. Ther. 110, 433-454. doi: 10.1016/j.pharmthera.2005.08.013

Camara, C. C., Araujo, C. V., de Sousa, K. K. O., Brito, G. A. C., Vale, M. L., Raposo, R. D. S., et al. (2015). Gabapentin attenuates neuropathic pain and

\section{FUTURE PROSPECTS}

Increased mechanistic study of the response of Schwann cells to nerve injury could reveal the underlying molecular mechanisms specific to neuropathic pain. The first pertinent approach would be to expand the recent development of conditional knockin/knockout mouse models to study the specific roles of target genes expressed in Schwann cells following nerve injury. Second, nonmyelinating Remak Schwann cells are characterized by a lack of myelin, but they also characteristically express cell surface receptors and cell adhesion molecules that are downregulated on myelinating Schwann cells. The difference between the two types of Schwann cells is a factor that merits additional study in the future. Third, neuropathic pain can result from different types of nerve injury or disease but has a higher prevalence in females than in males. How sex differences influence neuropathic pain must also be elucidated in future studies. Finally, drug targeting or transplantation of Schwann cells will be of great interest in the search for therapeutic strategies against neuropathic pain.

\section{AUTHOR CONTRIBUTIONS}

GC and ZW contributed to the conception and design of the review and wrote the first draft of the manuscript. ZW, GC, WS and YF wrote sections of the manuscript. All authors contributed to manuscript revision, read and approved the submitted version.

\section{FUNDING}

This work was supported by the National Key Research and Development Program of China (2017YFA0104704), the National Natural Science Foundation of China (31872773), the Basic Research Program of the Education Department of Jiangsu Province (17KJA180009), the Jiangsu Province Natural Science Foundation of China (BK20181460), and the Postgraduate Research \& Practice Innovation Program of Jiangsu Province (KYCX17-1906).

improves nerve myelination after chronic sciatic constriction in rats. Neurosci. Lett. 607, 52-58. doi: 10.1016/j.neulet.2015.09.021

Campana, W. M. (2007). Schwann cells: activated peripheral glia and their role in neuropathic pain. Brain Behav. Immun. 21, 522-527. doi: 10.1016/j.bbi.2006. 12.008

Campana, W. M., Li, X., Dragojlovic, N., Janes, J., Gaultier, A., and Gonias, S. L. (2006a). The low-density lipoprotein receptor-related protein is a pro-survival receptor in Schwann cells: possible implications in peripheral nerve injury. J. Neurosci. 26, 11197-11207. doi: 10.1523/JNEUROSCI.270906.2006

Campana, W. M., Li, X., Shubayev, V. I., Angert, M., Cai, K., and Myers, R. R. (2006b). Erythropoietin reduces Schwann cell TNF- $\alpha$, Wallerian degeneration and pain-related behaviors after peripheral nerve injury. Eur. J. Neurosci. 23, 617-626. doi: 10.1111/j.1460-9568.2006.04606.x

Chen, G., Kim, Y. H., Li, H., Luo, H., Liu, D. L., Zhang, Z. J., et al. (2017). PDL1 inhibits acute and chronic pain by suppressing nociceptive neuron activity via PD-1. Nat. Neurosci. 20, 917-926. doi: 10.1038/nn.4571

Chen, G., Luo, X., Qadri, M. Y., Berta, T., and Ji, R. R. (2018). Sex-dependent glial signaling in pathological pain: distinct roles of spinal microglia and astrocytes. Neurosci. Bull. 34, 98-108. doi: 10.1007/s12264-017-0145-y 
Chen, G., Park, C. K., Xie, R. G., Berta, T., Nedergaard, M., and Ji, R. R. (2014). Connexin-43 induces chemokine release from spinal cord astrocytes to maintain late-phase neuropathic pain in mice. Brain 137, 2193-2209. doi: 10.1093/brain/awu140

Chen, S., Velardez, M. O., Warot, X., Yu, Z. X., Miller, S. J., Cros, D., et al. (2006). Neuregulin 1-erbB signaling is necessary for normal myelination and sensory function. J. Neurosci. 26, 3079-3086. doi: 10.1523/JNEUROSCI.3785-05.2006

Chen, G., Xie, R. G., Gao, Y. J., Xu, Z. Z., Zhao, L. X., Bang, S., et al. (2016). $\beta$-arrestin-2 regulates NMDA receptor function in spinal lamina II neurons and duration of persistent pain. Nat. Commun. 7:12531. doi: $10.1038 /$ ncomms 12531

Chen, G., Zhang, Z., Wei, Z., Cheng, Q., Li, X., Li, W., et al. (2012). Lysosomal exocytosis in Schwann cells contributes to axon remyelination. Glia 60, 295-305. doi: 10.1002/glia.21263

Coccurello, R., Nazio, F., Rossi, C., De Angelis, F., Vacca, V., Giacovazzo, G., et al. (2018). Effects of caloric restriction on neuropathic pain, peripheral nerve degeneration and inflammation in normometabolic and autophagy defective prediabetic Ambral mice. PLoS One 13:e0208596. doi: 10.1371/journal.pone. 0208596

De Logu, F., Nassini, R., Materazzi, S., Carvalho Gonçalves, M., Nosi, D., Rossi Degl'Innocenti, D., et al. (2017). Schwann cell TRPA1 mediates neuroinflammation that sustains macrophage-dependent neuropathic pain in mice. Nat. Commun. 8:1887. doi: 10.1038/s41467-017-01739-2

Eid, S. R., Crown, E. D., Moore, E. L., Liang, H. A., Choong, K. C., Dima, S., et al. (2008). HC-030031, a TRPA1 selective antagonist, attenuates inflammatory- and neuropathy-induced mechanical hypersensitivity. Mol. Pain 4:48. doi: 10.1186/1744-8069-4-48

Faroni, A., Castelnovo, L. F., Procacci, P., Caffino, L., Fumagalli, F., Melfi, S., et al. (2014a). Deletion of GABA-B receptor in Schwann cells regulates remak bundles and small nociceptive C-fibers. Glia 62, 548-565. doi: 10.1002/glia. 22625

Faroni, A., Smith, R. J., Procacci, P., Castelnovo, L. F., Puccianti, E., Reid, A. J., et al. (2014b). Purinergic signaling mediated by P2X7 receptors controls myelination in sciatic nerves. J. Neurosci. Res. 92, 1259-1269. doi: 10.1002/jnr.23417

Faroni, A., Rothwell, S. W., Grolla, A. A., Terenghi, G., Magnaghi, V., and Verkhratsky, A. (2013). Differentiation of adipose-derived stem cells into Schwann cell phenotype induces expression of P2X receptors that control cell death. Cell Death Dis. 4:e743. doi: 10.1038/cddis.2013.268

Franchi, S., Valsecchi, A. E., Borsani, E., Procacci, P., Ferrari, D., Zalfa, C., et al. (2012). Intravenous neural stem cells abolish nociceptive hypersensitivity and trigger nerve regeneration in experimental neuropathy. Pain 153, 850-861. doi: $10.1016 /$ j.pain.2012.01.008

Gold, M. S., and Gebhart, G. F. (2010). Nociceptor sensitization in pain pathogenesis. Nat. Med. 16, 1248-1257. doi: 10.1038/nm.2235

Gonçalves, N. P., Vægter, C. B., Andersen, H., Østergaard, L., Calcutt, N. A., and Jensen, T. S. (2017). Schwann cell interactions with axons and microvessels in diabetic neuropathy. Nat. Rev. Neurol. 13, 135-147. doi: 10.1038/nrneurol. 2016.201

Griffin, J. W., and Thompson, W. J. (2008). Biology and pathology of nonmyelinating Schwann cells. Glia 56, 1518-1531. doi: 10.1002/glia.20778

Hartlehnert, M., Derksen, A., Hagenacker, T., Kindermann, D., Schäfers, M., Pawlak, M., et al. (2017). Schwann cells promote post-traumatic nerve inflammation and neuropathic pain through MHC class II. Sci. Rep. 7:12518. doi: 10.1038/s41598-017-12744-2

Hong, S., Remacle, A. G., Shiryaev, S. A., Choi, W., Hullugundi, S. K., Dolkas, J., et al. (2017). Reciprocal relationship between membrane type 1 matrix metalloproteinase and the algesic peptides of myelin basic protein contributes to chronic neuropathic pain. Brain Behav. Immun. 60, 282-292. doi: 10.1016/j. bbi.2016.11.003

Inoue, K. (2006). The function of microglia through purinergic receptors: neuropathic pain and cytokine release. Pharmacol. Ther. 109, 210-226. doi: 10.1016/j.pharmthera.2005.07.001

Inoue, M., Rashid, M. H., Fujita, R., Contos, J. J., Chun, J., and Ueda, H. (2004). Initiation of neuropathic pain requires lysophosphatidic acid receptor signaling. Nat. Med. 10, 712-718. doi: 10.1038/nm1060

Ishii, I., Fukushima, N., Ye, X., and Chun, J. (2004). Lysophospholipid receptors: signaling and biology. Annu. Rev. Biochem. 73, 321-354. doi: 10.1146/annurev. biochem.73.011303.073731
Jasmin, L., Vit, J. P., Bhargava, A., and Ohara, P. T. (2010). Can satellite glial cells be therapeutic targets for pain control? Neuron Glia Biol. 6, 63-71. doi: $10.1017 /$ s1740925x10000098

Jessen, K. R., and Arthur-Farraj, P. (2019). Repair Schwann cell update: adaptive reprogramming, EMT, and stemness in regenerating nerves. Glia 67, 421-437. doi: 10.1002/glia.23532

Ji, R. R., Berta, T., and Nedergaard, M. (2013). Glia and pain: is chronic pain a gliopathy? Pain 154, S10-S28. doi: 10.1016/j.pain.2013.06.022

Ji, R. R., Chamessian, A., and Zhang, Y. Q. (2016). Pain regulation by non-neuronal cells and inflammation. Science 354, 572-577. doi: $10.1126 /$ science.aaf8924

Ji, R. R., Kohno, T., Moore, K. A., and Woolf, C. J. (2003). Central sensitization and LTP: do pain and memory share similar mechanisms? Trends Neurosci. 26, 696-705. doi: 10.1016/j.tins.2003.09.017

Keswani, S. C., Buldanlioglu, U., Fischer, A., Reed, N., Polley, M., Liang, H., et al. (2004). A novel endogenous erythropoietin mediated pathway prevents axonal degeneration. Ann. Neurol. 56, 815-826. doi: 10.1002/ana.20285

Keswani, S. C., Jack, C., Zhou, C., and Höke, A. (2006). Establishment of a rodent model of HIV-associated sensory neuropathy. J. Neurosci. 26, 10299-10304. doi: 10.1523/JNEUROSCI.3135-06.2006

Kidd, G. J., Ohno, N., and Trapp, B. D. (2013). Biology of Schwann cells. Handb. Clin. Neurol. 115, 55-79. doi: 10.1016/B978-0-444-52902-2.00005-9

Kuan, Y. H., and Shyu, B. C. (2016). Nociceptive transmission and modulation via P2X receptors in central pain syndrome. Mol. Brain 9:58. doi: 10.1186/s13041016-0240-4

Kuner, R. (2010). Central mechanisms of pathological pain. Nat. Med. 16, 1258-1266. doi: 10.1038/nm.2231

Lecca, D., Ceruti, S., Fumagalli, M., and Abbracchio, M. P. (2012). Purinergic trophic signalling in glial cells: functional effects and modulation of cell proliferation, differentiation, and death. Purinergic Signal. 8, 539-557. doi: 10.1007/s11302-012-9310-y

Lee, H., Lee, S., Cho, I. H., and Lee, S. J. (2013). Toll-like receptors: sensor molecules for detecting damage to the nervous system. Curr. Protein Pept. Sci. 14, 33-42. doi: 10.2174/1389203711314010006

Li, X., Gonias, S. L., and Campana, W. M. (2005). Schwann cells express erythropoietin receptor and represent a major target for Epo in peripheral nerve injury. Glia 51, 254-265. doi: 10.1002/glia.20202

Liu, H., Shiryaev, S. A., Chernov, A. V., Kim, Y., Shubayev, I., Remacle, A. G., et al. (2012). Immunodominant fragments of myelin basic protein initiate T cell-dependent pain. J. Neuroinflammation 9:119. doi: 10.1186/1742-20 94-9-119

Magnaghi, V., Ballabio, M., Cavarretta, I. T., Froestl, W., Lambert, J. J., Zucchi, I., et al. (2004). GABAB receptors in Schwann cells influence proliferation and myelin protein expression. Eur. J. Neurosci. 19, 2641-2649. doi: 10.1111/j.0953816x.2004.03368.x

Magnaghi, V., Ballabio, M., Consoli, A., Lambert, J. J., Roglio, I., and Melcangi, R. C. (2006). GABA receptor-mediated effects in the peripheral nervous system: a cross-interaction with neuroactive steroids. J. Mol. Neurosci. 28, 89-102. doi: 10.1385/jmn:28:1:89

Magnaghi, V., Castelnovo, L. F., Faroni, A., Cavalli, E., Caffino, L., Colciago, A., et al. (2014). Nerve regenerative effects of GABA-B ligands in a model of neuropathic pain. Biomed. Res. Int. 2014:368678. doi: 10.1155/2014/368678

Mantuano, E., Henry, K., Yamauchi, T., Hiramatsu, N., Yamauchi, K., Orita, S., et al. (2011). The unfolded protein response is a major mechanism by which LRP1 regulates Schwann cell survival after injury. J. Neurosci. 31, 13376-13385. doi: 10.1523/JNEUROSCI.2850-11.2011

Marinelli, S., Nazio, F., Tinari, A., Ciarlo, L., D’Amelio, M., Pieroni, L., et al. (2014). Schwann cell autophagy counteracts the onset and chronification of neuropathic pain. Pain 155, 93-107. doi: 10.1016/j.pain.2013.09.013

Marinelli, S., Vacca, V., Ricordy, R., Uggenti, C., Tata, A. M., Luvisetto, S., et al. (2012). The analgesic effect on neuropathic pain of retrogradely transported botulinum neurotoxin A involves Schwann cells and astrocytes. PLoS One 7:e47977. doi: 10.1371/journal.pone.0047977

Martucci, C., Trovato, A. E., Costa, B., Borsani, E., Franchi, S., Magnaghi, V., et al. (2008). The purinergic antagonist PPADS reduces pain related behaviours and interleukin- $1 \beta$, interleukin-6, iNOS and nNOS overproduction in central and peripheral nervous system after peripheral neuropathy in mice. Pain 137, 81-95. doi: 10.1016/j.pain.2007.08.017 
Mayer, C., Quasthoff, S., and Grafe, P. (1998). Differences in the sensitivity to purinergic stimulation of myelinating and non-myelinating Schwann cells in peripheral human and rat nerve. Glia 23, 374-382. doi: 10.1002/(sici)10981136(199808)23:4<374::aid-glia9 > 3.0.co;2-2

Meyer zu Hörste, G., Heidenreich, H., Lehmann, H. C., Ferrone, S., Hartung, H. P., Wiendl, H., et al. (2010a). Expression of antigen processing and presenting molecules by Schwann cells in inflammatory neuropathies. Glia 58, 80-92. doi: 10.1002/glia.20903

Meyer zu Hörste, G., Heidenreich, H., Mausberg, A. K., Lehmann, H. C., ten Asbroek, A. L., Saavedra, J. T., et al. (2010b). Mouse Schwann cells activate MHC class I and II restricted T-cell responses, but require external peptide processing for MHC class II presentation. Neurobiol. Dis. 37, 483-490. doi: 10.1016/j.nbd.2009.11.006

Mizisin, A. P. (2014). Mechanisms of diabetic neuropathy: schwann cells. Handb. Clin. Neurol. 126, 401-428. doi: 10.1016/B978-0-444-53480-4.00029-1

Neefjes, J., Jongsma, M. L., Paul, P., and Bakke, O. (2011). Towards a systems understanding of MHC class I and MHC class II antigen presentation. Nat. Rev. Immunol. 11, 823-836. doi: 10.1038/nri3084

Nicotra, L., Loram, L. C., Watkins, L. R., and Hutchinson, M. R. (2012). Toll-like receptors in chronic pain. Exp. Neurol. 234, 316-329. doi: 10.1016/j.expneurol. 2011.09.038

Offermanns, S. (2017). Hydroxy-carboxylic acid receptor actions in metabolism. Trends Endocrinol. Metab. 28, 227-236. doi: 10.1016/j.tem.2016.11.007

Oh, H. M., and Chung, M. E. (2015). Botulinum toxin for neuropathic pain: a review of the literature. Toxins 7, 3127-3154. doi: 10.3390/toxins7083127

Orita, S., Henry, K., Mantuano, E., Yamauchi, K., De Corato, A., Ishikawa, T., et al. (2013). Schwann cell LRP1 regulates remak bundle ultrastructure and axonal interactions to prevent neuropathic pain. J. Neurosci. 33, 5590-5602. doi: 10.1523/JNEUROSCI.3342-12.2013

Park, H., and Poo, M. M. (2013). Neurotrophin regulation of neural circuit development and function. Nat. Rev. Neurosci. 14, 7-23. doi: 10.1038/nrn3379

Procacci, P., Ballabio, M., Castelnovo, L. F., Mantovani, C., and Magnaghi, V. (2012). GABA-B receptors in the PNS have a role in Schwann cells differentiation? Front. Cell. Neurosci. 6:68. doi: 10.3389/fncel.2012.00068

Sacerdote, P., Franchi, S., Trovato, A. E., Valsecchi, A. E., Panerai, A. E., and Colleoni, M. (2008). Transient early expression of TNF- $\alpha$ in sciatic nerve and dorsal root ganglia in a mouse model of painful peripheral neuropathy. Neurosci. Lett. 436, 210-213. doi: 10.1016/j.neulet.2008.03.023

Scheib, J., and Höke, A. (2013). Advances in peripheral nerve regeneration. Nat. Rev. Neurol. 9, 668-676. doi: 10.1038/nrneurol.2013.227

Scholz, J., and Woolf, C. J. (2007). The neuropathic pain triad: neurons, immune cells and glia. Nat. Neurosci. 10, 1361-1368. doi: 10.1038/nn1992

Sorge, R. E., LaCroix-Fralish, M. L., Tuttle, A. H., Sotocinal, S. G., Austin, J. S., Ritchie, J., et al. (2011). Spinal cord Toll-like receptor 4 mediates inflammatory and neuropathic hypersensitivity in male but not female mice. J. Neurosci. 31, 15450-15454. doi: 10.1523/JNEUROSCI.3859-11.2011

Story, G. M., Peier, A. M., Reeve, A. J., Eid, S. R., Mosbacher, J., Hricik, T. R., et al. (2003). ANKTM1, a TRP-like channel expressed in nociceptive neurons, is activated by cold temperatures. Cell 112, 819-829. doi: 10.1016/s00928674(03)00158-2

Su, W. F., Gu, Y., Wei, Z. Y., Shen, Y. T., Jin, Z. H., Yuan, Y., et al. (2016). Rab27a/Slp2-a complex is involved in Schwann cell myelination. Neural Regen. Res. 11, 1830-1838. doi: 10.4103/1673-5374.194755

Su, W. F., Wu, F., Jin, Z. H., Gu, Y., Chen, Y. T., Fei, Y., et al. (2019). Overexpression of $\mathrm{P} 2 \mathrm{X} 4$ receptor in Schwann cells promotes motor and sensory functional recovery and remyelination via BDNF secretion after nerve injury. Glia 67, 78-90. doi: 10.1002/glia.23527
Takahashi, M., Kawaguchi, M., Shimada, K., Konishi, N., Furuya, H., and Nakashima, T. (2004). Cyclooxygenase-2 expression in Schwann cells and macrophages in the sciatic nerve after single spinal nerve injury in rats. Neurosci. Lett. 363, 203-206. doi: 10.1016/j.neulet.2004.03.040

Tao, F., Li, Q., Liu, S., Wu, H., Skinner, J., Hurtado, A., et al. (2013). Role of neuregulin-1/ErbB signaling in stem cell therapy for spinal cord injury-induced chronic neuropathic pain. Stem Cells 31, 83-91. doi: 10.1002/stem. 1258

Toews, A. D., Barrett, C., and Morell, P. (1998). Monocyte chemoattractant protein 1 is responsible for macrophage recruitment following injury to sciatic nerve. J. Neurosci. Res. 53, 260-267. doi: 10.1002/(sici)10974547(19980715)53:2<260::aid-jnr15 > 3.0.co;2-a

Tsuda, M., Shigemoto-Mogami, Y., Koizumi, S., Mizokoshi, A., Kohsaka, S., Salter, M. W., et al. (2003). P2X4 receptors induced in spinal microglia gate tactile allodynia after nerve injury. Nature 424, 778-783. doi: $10.1038 /$ nature 01786

Tsuda, M., Tozaki-Saitoh, H., and Inoue, K. (2010). Pain and purinergic signaling. Brain Res. Rev. 63, 222-232. doi: 10.1016/j.brainresrev.2009.11.003

Ulmann, L., Hatcher, J. P., Hughes, J. P., Chaumont, S., Green, P. J., Conquet, F., et al. (2008). Up-regulation of P2X4 receptors in spinal microglia after peripheral nerve injury mediates BDNF release and neuropathic pain. J. Neurosci. 28, 11263-11268. doi: 10.1523/JNEUROSCI.230808.2008

Verdiyan, E. E., Allakhverdiev, E. S., and Maksimov, G. V. (2016). Study of the peripheral nerve fibers myelin structure changes during activation of schwann cell acetylcholine receptors. PLoS One 11:e0158083. doi: 10.1371/journal.pone. 0158083

Wallace, V. C., Cottrell, D. F., Brophy, P. J., and Fleetwood-Walker, S. M. (2003). Focal lysolecithin-induced demyelination of peripheral afferents results in neuropathic pain behavior that is attenuated by cannabinoids. J. Neurosci. 23, 3221-3233. doi: 10.1523/JNEUROSCI.23-08-03221.2003

Wang, Z. H., Zeng, X. Y., Han, S. P., Fan, G. X., and Wang, J. Y. (2012). Interleukin10 of red nucleus plays anti-allodynia effect in neuropathic pain rats with spared nerve injury. Neurochem. Res. 37, 1811-1819. doi: 10.1007/s11064-0120795-0

Weiner, J. A., Fukushima, N., Contos, J. J., Scherer, S. S., and Chun, J. (2001). Regulation of Schwann cell morphology and adhesion by receptormediated lysophosphatidic acid signaling. J. Neurosci. 21, 7069-7078. doi: 10.1523/JNEUROSCI.21-18-07069.2001

Yajima, Y., Narita, M., Usui, A., Kaneko, C., Miyatake, M., Narita, M., et al. (2005). Direct evidence for the involvement of brain-derived neurotrophic factor in the development of a neuropathic pain-like state in mice. J. Neurochem. 93, 584-594. doi: 10.1111/j.1471-4159.2005.03045.x

Zhang, Y. L., Liu, Y. G., Chen, D. J., Yang, B. L., Liu, T. T., Li, J. J., et al. (2018). Microencapsulated Schwann cell transplantation inhibits $\mathrm{P} 2 \mathrm{X} 2 / 3$ receptors overexpression in a sciatic nerve injury rat model with neuropathic pain. Neurosci. Lett. 676, 51-57. doi: 10.1016/j.neulet.2018.03.063

Conflict of Interest Statement: The authors declare that the research was conducted in the absence of any commercial or financial relationships that could be construed as a potential conflict of interest.

Copyright (C) 2019 Wei, Fei, Su and Chen. This is an open-access article distributed under the terms of the Creative Commons Attribution License (CC BY). The use, distribution or reproduction in other forums is permitted, provided the original author(s) and the copyright owner(s) are credited and that the original publication in this journal is cited, in accordance with accepted academic practice. No use, distribution or reproduction is permitted which does not comply with these terms. 